\title{
Technology Research and Design on The New Device of Drilling Fluid Mixing
}

\author{
Chen Yanguo \\ School of Petroleum Engineering \\ Chongqing University of Science \& Technology, \\ Chongqing, China \\ $1131824211 @ q q . c o m$
}

\author{
Jiang Yurong* \\ School of Petroleum Engineering \\ Chongqing University of Science \& Technology, \\ Chongqing, China \\ *381012115@qq.com(Corresponding author)
}

\author{
Zhang Yage \\ School of Petroleum Engineering \\ Chongqing University of Science \& Technology, \\ Chongqing, China \\ 289547695@qq.com \\ Yu Xinke \\ School of Petroleum Engineering \\ Chongqing University of Science \& Technology, \\ Chongqing, China \\ 903108418@qq.com
}

\begin{abstract}
In the process of oil and nature gas drilling, the drilling fluid density is a very important parameter, which is one of the key factors of drilling safety. In the drilling process it is important to adjust the drilling fluid density rapidly according to the formation pressure. However, the efficiency of existed adjustment device of drilling fluid density mixing is low, slow and unstable for the need of drilling fluid. In this paper, the finite element simulation and structure design were carried out to study the new device of drilling fluid mixing which includes fluidic element, mixing chamber and outlet pipe. The experiment results show that the new device has the advantages of high efficiency, small size and good maneuverability.
\end{abstract}

Keywords-drilling fluid mixing device;fluidic element;finite element simulation; experiment;structure design

\section{INTRODUCTION}

In the process flow of petroleum, chemical, pharmaceutical, beverage, brewing and other industries, it is needed to mix a few ( 2 or 3 ) kinds of liquids in a certain ratio in order to adjust the density or deal with them accordingly[1-3]. Especially the drilling fluid is an important part of the oil and gas drilling engineering. Two methods are commonly used today [4-6]: one is artificial, pumping two liquids into the storage container according to the mixing ratio intermittently and quantificational to stir to mix. The other method is using the computers to pump the two liquids continuously into the storage container with the flow detection device respectively detecting the flow of both liquids, and then transforming them into electrical signals transmitting to the computer which will calculate the ratio of the two to compare with the required mixing ratio.

The first method has the advantage of easy to control and accurate, but cannot make continuously-mixing production, thus often used in the production of a small quantity of substance[7,8]. The second one could be controlled precisely and make continuous production, but the process is relatively complicated, and the devices cost much at the same time[9-11]. Besides, both methods need a storage container of large capacity and mixing devices which have large volumes and a lot of movable sections which make them fragile, so they are not suitable for rapid and stable mixing adjustment, neither are they suitable for some occasions which has limited space.

In the process of drilling construction, the performance adjustment configuration and processing compound of drilling fluid have many defects[12-14,21]. One defect is that the betonies and all kinds of drilling fluid treatment agent cannot fully dissolved and dispersed with the lowly drilling treating efficiency. The second is that the drilling fluid handling uneven, which affects the quality of drilling fluid and cause the down hole complex processing. The third is that the aggravating cause dust pollution and waste stone powder and so on. For the above defects, it is important to develop a kind of drilling fluid and can prevent the dust pollution of the device. It can improve the quality of drilling fluid with lower consumption and saving the cost of drilling.Therefore,we designed the new device of drilling fluid mixing device.

This device is designed with the principle of fluid mechanics, according to the proper design of the mixing chamber, baffle structure and flow channel and so on. A new type of multi-purpose fluid mixing device was developed. This fluid device has the advantages of high efficiency, small size, good maneuverability and larger flow which could realize the non-additional-energy mixing, and it is simple, practical, highly operable with little requirement of space and easy to maintain. This device can be widely applied in petrochemical industry, which can especially meet the requirement of the mud density adjustment of oil drilling and the space need of offshore drilling platform. It also has the ability to quickly get the proper mud density to achieve the goal of balance formation pressure[15-21].The device not only could be used for regular production, but also can be used as an emergency equipment to prevent and deal with blowout, leakage and collapse. 


\section{STRUCTURE DESIGN AND MIXING PRINCIPLE}

\section{A. The structure design of the new device of drilling} fluid mixing

Shown in Fig. 1 is the main structure of the new device of drilling fluid mixing. The main body device uses the theory of fluid mechanics, through the reasonable design of mixing chamber, baffle structure and flow channel to improve the effect of mixing. The body device includes the jet system, the hybrid system and the export hybrid system.

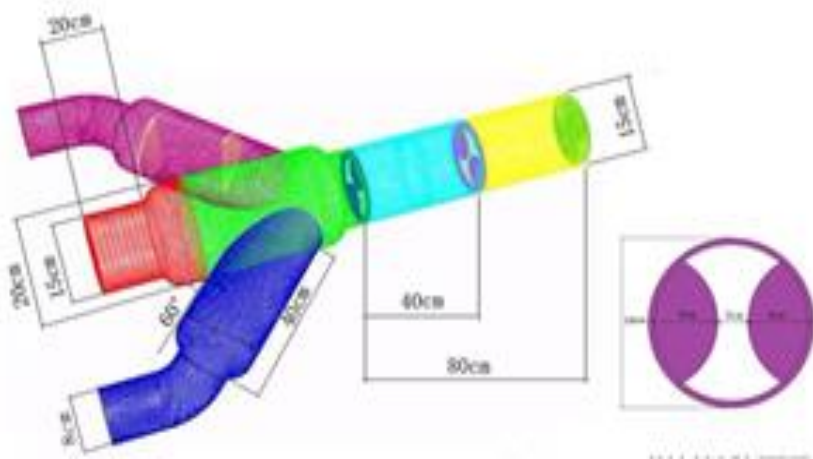

Figure 1. Drilling fluid mixing device

The entries of the equipment can be composed by three imported butterfly valves and three flow meters, according to the density and flow requirements to adjust the inlet fluid flow which can realize the adjustment of the density of drilling fluid. There are two mutually vertical baffles in the exit of the DN150 outlet pipe which can change the flow state if the drilling fluid. The mixing effect can be highly improved by the kind of structure in the small space.

\section{B. Mixing principle}

The new device of drilling fluid mixing mainly used the rheological change principle of engineering fluid mechanics basics theory. The jet mixers in the suction pipeline go into the mixer with an angle and On the export pipeline, the baffles are used to change the flow of the fluid in the pipe to make further mixing fluid. According to the design of mixer, it can be realized for two or three kinds of rapid mixing of fluids and the density adjustment without preparation in advance, artificial mixing and don't need to set up the moving parts.

Firstly, the jet systems are mainly used to increase the pressure, control the fluid flow so as to enhance mixing effect. Secondly, the hybrid system are mainly used to extend the time of mixing, slow the flow velocity to increase mixing effect. At last, the export hybrid system of two groups of symmetric damper structure are mainly used to change the direction of flow turbulence formation witch can increase the mixing effect further more.

\section{FINITE ELEMENT SIMULATION AND EXPERIMENTS}

\section{A. The results of finite element simulation}

The finite element analysis software of Fulent was used to simulate mixing effect of the device. The results were showed in the Fig.2-6.

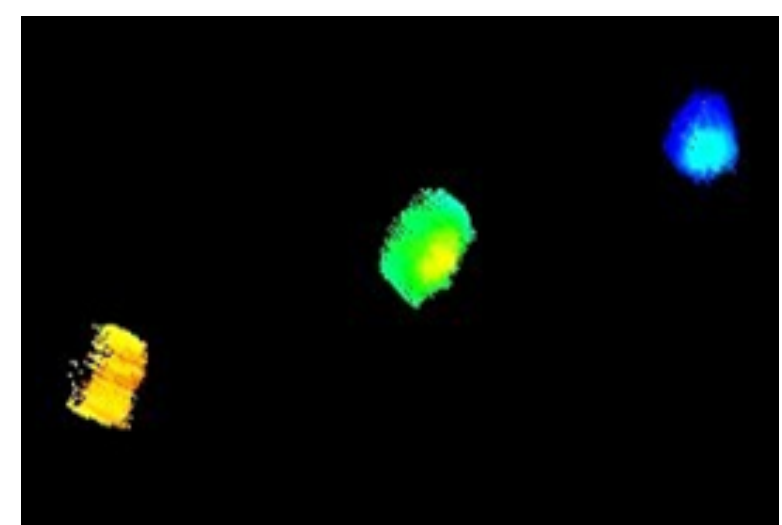

Figure 2. Three kinds of fluid through the pump into the pipeline

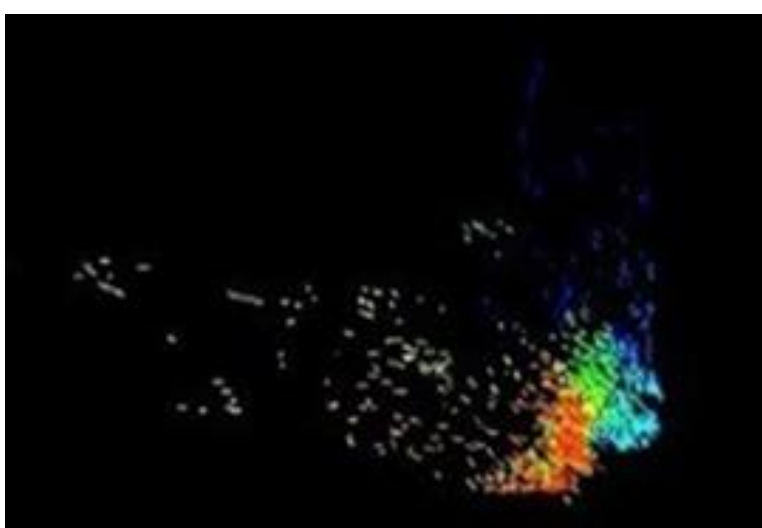

Figure 3. Through the nozzle jet in the main cavity in the body for first mix

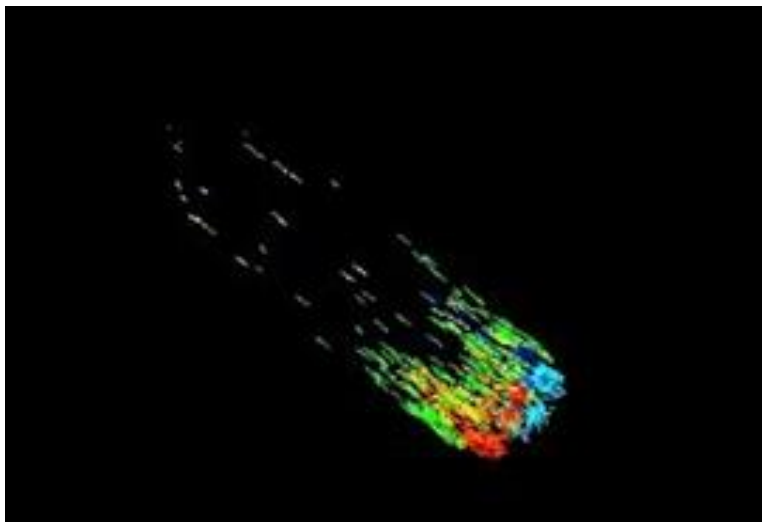

Figure 4. .Mixing effect after the two baffle

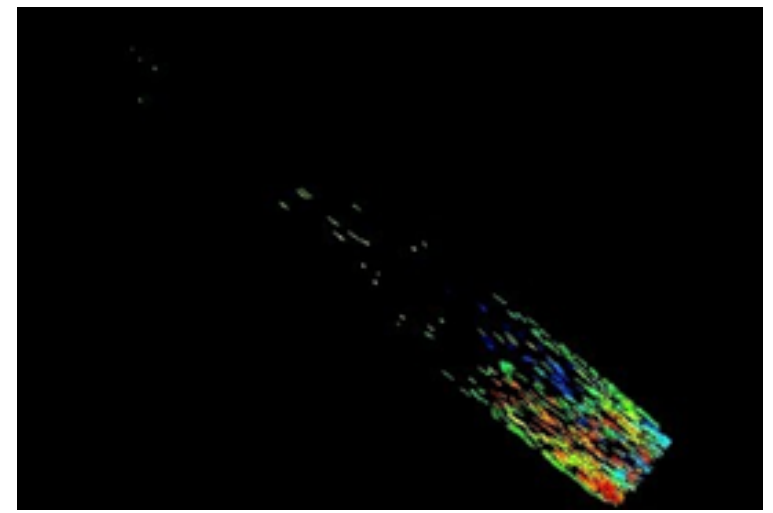

Figure 5. Mixing complete outflow pipe 


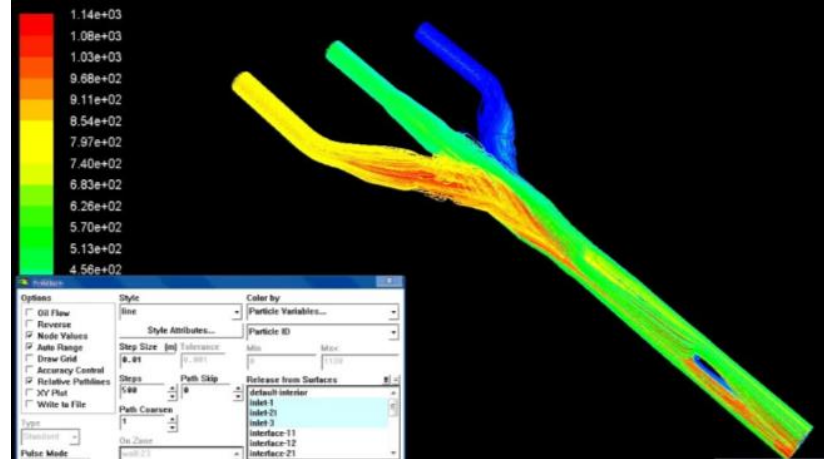

Figure 6. Overall hybrid simulation effect of the new device

It can be seen in Fig.2-6. that the three fluids changed the flow state after the entrance to the jet pipe of the fluidic element and they are mixed in the main mixing chamber mixture for the first time. Then within the export mix section of two groups of symmetrical baffle structure change flow state again, so as to enhance the mixing effect further and the mixing effect is better at the exit.

\section{B. The experiment principles and parameters}

The scaling device of the new device was used for pilot experiment to test and verify the density adjustment and mixing effect. Pilot experiment used two kinds of fluids to simulate the fluid mixing. One kind of the fluids were the mud with the density of $1.13 \mathrm{~g} / \mathrm{cm}^{3}$ and $1.18 \mathrm{~g} / \mathrm{cm}^{3}$ and the water with the density of $1.08 \mathrm{~g} / \mathrm{cm}^{3}$. In the pilot experiments, all the flows of fluids were equal.

By random sampling in the process of mixing, the sampling position distribution in the export of the circumference of the liquid column and the middle part which is to determine the density of the different parts of the fluid, so as to realize the overall mix effect.

\section{The experimental results}

The density of liquid was shown in Table I and Table II, the theory and the actual fluid density results as shown in Fig. 7.

TABLE I. TWO KINDS OF FLUIDS MIXING,THE DENSITY OF LIQUID SAMPLES

\begin{tabular}{|c|c|c|c|c|c|c|}
\hline $\begin{array}{c}\text { Liquid } \\
\text { samples }\end{array}$ & 1 & 2 & 3 & 4 & 5 & 6 \\
\hline $\begin{array}{c}\text { Density } \\
\left(\mathbf{g} / \mathbf{c m}^{\mathbf{3}}\right)\end{array}$ & 1.119 & 1.120 & 1.120 & 1.121 & 1.119 & 1.120 \\
\hline
\end{tabular}

TABLE II. THREE KINDS OF FLUIDS MIXING,THE DENSITY OF LIQUID SAMPLES

\begin{tabular}{|c|c|c|c|c|c|c|}
\hline $\begin{array}{c}\text { Liquid } \\
\text { samples }\end{array}$ & 1 & 2 & 3 & 4 & 5 & 6 \\
\hline $\begin{array}{c}\text { Density } \\
\left(\mathbf{g} / \mathrm{cm}^{3}\right)\end{array}$ & 1.129 & 1.129 & 1.130 & 1.130 & 1.131 & 1.130 \\
\hline
\end{tabular}

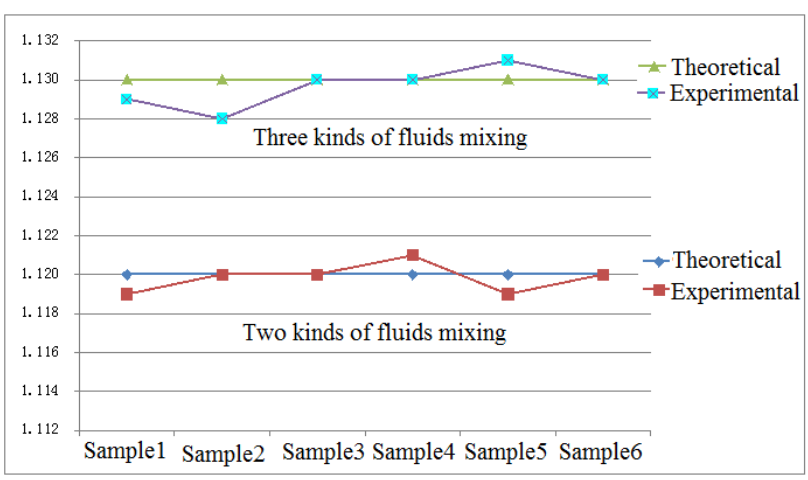

Figure 7. Fluid density of the experiment results

It can be seen from Table I, Table II and Fig.7,every 30 seconds from mixing random sampling of the six different perspectives on the fluid density is very closed to the theoretical value, both within an error of $5 \%$.The performance of this mixing device is stable, and the mixing effect is good.

It was benefits from the design of the scientific theory and the reasonable design of related parts. Some measuring density of the sample with the theoretical value has a little deviation, the clay in the laboratory may be a bit metamorphism and harden, or caused by measuring the operation.

\section{THE TECHNOLOGY INNOVATIONS AND ADVANTAGES OF THE NEW DEVICE}

\section{A. The innovation of technology}

The technology innovations of the new device mainly includes:

1) Set up three fluid jet pipe entrance, entrance jet tube set with jet element to enhance the mixing effect;

2) The main hybrid cavity increase to slow the velocity of flow and extend the mixing time;

3) In order to enhance the mixing effect further, export mix section has a symmetrical baffle structure is installed inside.

Compared to the conventional drilling fluid mixing device, the new type of drilling fluid mixing device has the advantages of perfect mixing effect, portable easily to install and tear down, long life of using and lower economic cost.

\section{B. The advantages of device}

Existing fluid density regulating device are needed for large capacity storage containers and mixing equipment, the equipment is large, more moving equipment and parts, easy to damage, The China National Offshore Oil Corporation has launched "863" scientific research project "the surface of deep water key technology of drilling and the research of equipment" , including our school took on corpus the research of "the density of mud dynamic adjusting device "[1].

The equipment control accuracy is high, the mud mixing effect is wonderful, but large, complex process, the cost is too high, isn't conducive to plant the popularization and application. Can't satisfy the similar offshore drilling fluid mixed preparation in the process of rapid, stable, high reliability and space requirements. 
New type of drilling fluid mixing device has the following advantages compared with the conventional drilling fluid mixing device:

1)Mixing effect is perfect

New drilling fluid mixing device using the fluid mechanics principle, through reasonable design of mixing chamber, the structure of the baffle and port, etc. effectively improve the fluid mixing effect.

2)Portable, easy to install and tear down

Compared with conventional drilling fluid mixing device the device is more light, concise, saves the space greatly, the operation of installation, dismantlement, mobile and only 2 people can finish, save manpower and material resources, production expenses increased greatly.

3)Long life

The service life of the ordinary mixing device for 2 years or so commonly, but the new type of drilling fluid mixed quickly adjusting device can be timely replacement parts necessary because of it's convenient and easy to remove to realize the extension of product life.

4)Saving economic cost

The device can be realized fast mixing and density adjustment of the drilling fluid without configuration, artificial mixing and don't need to set the moving parts. Saving the cost of artificial and power, increasing the yield of the product.

\section{CONCLUSIONS}

Through simulation experiment and pilot experiment, it can be seen that the fluid mixing device has excellent mixing effect by using the theory of fluid mechanics, the reasonable design of mixing chamber, the structure of the baffle and port, etc. The new drilling fluid mixing device is a kind of equipment which has high mixed effect, and two or three different fluids can be mixed quickly at the same time.

By comparing with the traditional domestic drilling fluid mixing device, the mixing device can realize not only two or three different rapid mixing of fluid, density adjustment, also covers the characteristics of an area of small and light weight. So the hose connection can be used to make the new drilling fluid fast mix adjusting device placed anywhere in the factory, make it's application range is increased greatly.

At the same time, the device can be timely replacement parts necessary to achieve the extension of the product life and reduce the economic cost; It's normal work without configuration, artificial mixing in advance and don't need to set up the moving parts shows that the device can be realized the maneuverability is strong with the lower labor costs.

\section{REFERENCES}

[1] Kong Songtao,Lei Zongming," The research of drilling fluid mixing mechanism, petroleum machinery" ,Vol.38,No.11,2010

[2] Liu Yan,Yu Xuyang, " The research of drilling fluid mixing,petroleum machinery" , Vol.41,No.1,2013

[3] J. Hermoso;F. Martinez-Boza;C. Gallegos," Applied Clay Science”, Vol.87,pp14-21, 2014.

[4] .Hermoso, J.;Jofore, B. D.;Martínez-Boza, F. J.;Gallegos, C.” Industrial \& Engineering Chemistry Research", Vol.51,No.44, pp14399-14407.

[5] Griffin, Jeff," Underground Construction", Vol.56, No.6,pp58, 2001.

[6] Zhu, Z.;Li, J.;Xie, S.;Yuan, G.” Petroleum Science and Technology, Vol.29, No.14, pp1470-1481, 2011.

[7] David C. Thomas;James F. Lea Jr.;E.A. Turek," Journal of Petroleum Technology", Vol.36, No.6,pp959-968, 1984.

[8] Paul, Don;Mercer, Robert," Offshore”, Vol.58, No.8,pp64, 1999.

[9] Andreas Hartmann, Renate Pechnig and Christoph Clauser," International Journal of Earth Sciences", Vol.97, NO.2,pp421-433, 2008.

[10] Griffin, Jeff, "Underground Construction", Vol.56, No.9,pp56, 2001.

[11] Leonard-Barton, Dorothy;Sviokla, John J," Harvard Business Review", Vol.66, No.2,pp91-98, 1988.

[12] M.M. Dardir;S. Ibrahime;M. Soliman;S.D. Desouky;A.A. Hafiz," Egyptian Journal of Petroleum", Vol.23, No.1,pp35-43, 2014.

[13] Oil, Gas \& Petrochem Equipment Group," Oil, Gas \& Petrochem Equipment", Vol.54, No.6, 2008.

[14] Anonymous," National Driller", Vol.32, No.1,pp56-57, 2011.

[15] Steinsvag, Kjersti;Galea, Karen S.;Kruger, Kirsti;Peikli, Vegard;Sanchez-Jimenez, Araceli;Saetvedt, Esther;Searl, Alison;Cherrie, John W.;van Tongeren, Martie," Annals of Occupational Hygiene", Vol.55, No.4,pp347-356, 2011.

[16] Blanc, Leonard," Offshore", Vol.56, No.3,pp20, 1996.

[17] Griffin, Jeff," Underground Construction", Vol.56, No.12,pp46, 2001.

[18] Pipeline and Utilities Construction”, Vol.51, No.9,pp66, 1996.

[19] Yigit, Ahmet S.;Christoforou, Andreas P," Journal of Energy Resources Technology", Vol.128, No.4,pp268-274, 2006.

[20] Lea, James F.;Winkler, Herald W.;Snyder, Robert E.Oyewole, Peter O," World Oil", Vol.229, No.5,pp9, 2008.

[21] Chen Qingyao,Wang Jiangli, ” The equipment and use of automatic drilling fluid mixing, petroleum machinery” ,Vol.28,No.4,1999 